\title{
All cost effective treatments should be free ... or, how Archie Cochrane changed my life!
}

\author{
Alan Williams
}

I must be one of the few people to have met Archie Cochrane without realising they had done so. It happened in 1968 when I was on a two year secondment to the Treasury. Part of my role there was to act as a roving economist, going into various other departments which were still in a state of innocence (ie, which had no economists of their own); the idea being that I would help them to solve their problems. In some cases the problem I was asked to solve was one that the host department didn't know it had, and so it was with my roving commission in the Ministry of Health. At that time the hospital building programme was in full swing, and the Treasury were anxious to find out when it would begin to tail off. The idea was that I would use whatever criteria were currently being applied to determine the size of the programme and its distribution, and then, on that basis, project the future volume of expenditure and estimate when the criteria were likely to be satisfied so that the level of expenditure would fall. It was all a bit like the expectation that once a backlog of accumulated illness has been cleared, NHS expenditure would decline to, and settle at, a lower level.

If I were to tell you there were no criteria, that probably wouldn't surprise you, but it would not be quite true. As regards the volume of the programme, the criterion seemed to be to squeeze as much out of the Treasury as could be got - and since building new hospitals was a great vote catcher, and opening them provided wonderful photo opportunities for politicians and other self important people, the pressure to keep on building them was hard to resist. (I'm sure I don't have to tell you that closing hospitals is an entirely different matter!) And as regards the distribution of these new hospitals, the criterion seemed to be a geographically determined version of "Buggins's turn", with a vague commitment to give priority to replacing the older hospitals first. On closer inspection, the age of a hospital proved to be a rather slippery concept, since on the same site you frequently find buildings spanning more than a century, the older ones typically having been periodically upgraded and adapted to new uses. So determining the age of a hospital was a fine art which allowed plenty of scope for artistic licence! When I asked how old a hospital had to be to be regarded as "old", I got some rather shifty answers, and my general impression was that the basic idea was that if the money could be kept flowing, then in 30 or 40 years time it would be time to replace the hospitals that were being built now, so the notion that the building programme might one day "tail off" was a completely alien concept within the Ministry of Health.

I thus reported to the Treasury, which promptly sent me back to find some criteria which would ensure that it tailed off. Well, I had been brought up with a deep belief in the universality of the law of diminishing marginal returns, so on the second round I tried a different tack. It must, I thought, be the case that new hospitals are more cost effective than old ones, but that this differential advantage would slowly decline as more new hospitals were built, and as the average age of the remaining stock declined. It did not take long to discover that new hospitals not only cost a lot of money to build, but once built they cost far more money to run than old ones did. I then naively explored the possibility that this must be outweighed by the fact that new hospitals are much more effective than old ones. "Effective? What do you mean 'effective'?" I cast about desperately. - "Does the health of the local population improve when their old hospital is replaced by a new one?" Answer: "Hard to say . . . but probably not noticeably."

- Question: "Has anyone ever done a study comparing the impact on people's health of new hospitals compared with old ones?" Answer: "Good God no. . . . It wouldn't be possible. . . .!"

So my second report to the Treasury was rather more startling than the first, saying that new hospitals were certainly more costly in every respect than old ones, they were probably no more effective, so they were almost certainly less cost effective. Hence, new hospital building was not a good investment.

At this point the argument escalated in the official hierarchy, with the Treasury wheeling in some big guns (you will appreciate that I was just a lowly foot soldier who had been sent out on a reconnaissance mission). So the Ministry of Health assembled its big battalions too, including leading members of the medical/ scientific establishment, whose names and faces meant absolutely nothing to me. They asserted firmly that new hospitals were better than old ones, as anyone who had ever worked in a hospital would know (this last remark being accompanied by pointed glances in my dir- 
ection). My rather lame protestations that I would be more impressed if some hard evidence could be produced, elicited the retort that it was hard to see what more compelling evidence one could expect than the unanimous view of the people with the most relevant experience. But, they added condescendingly, if I thought that more was needed, then I should perhaps specify what it should be, and how it might be collected and used. So I went away with my tail between my legs, wondering what on earth to do next, since my superiors in the Treasury were not in a mood to give up.

Now it so happened that one of my earlier roving commissions had been to work in the Home Office on the efficiency of police services. There I had had contact with some operational research people who had devised an index of crime seriousness, which they had used to measure the effectiveness of the police in reducing the level of crime. They had also used it to try to get police resources redirected towards the crimes which the public regarded as the most serious. So I thought to myself Why should we not have an index of illness seriousness along the same lines, to measure the effectiveness of hospitals, and to redirect NHS resources towards conditions which the public regard as the most serious? So I sat down and listed a few obvious attributes of illness which I thought most people would care about, such as disability and distress and loss of life expectancy. And I drew up a sketchy plan about how such information might be collected and deployed to measure how much better off in health terms a population might be when they get a new hospital in place of their old one. Armed with this I went back into the fray.

Needless to say, I got nowhere. The experts dismissed these ideas as impractical. I moved on to my next assignment, which might have been rural water supplies in Shropshire, or Britain's role in the European space programme, or the optimal size of prisons . . . I do not recall precisely the order in which these things came my way. The Treasury decided to give up on economic evaluation of the hospital building programme and go back to the old tried and trusted administrative methods of dealing with such situations, namely just cutting back on the capital programme and letting the Ministry of Health sort out the consequences. But I did note that shortly afterwards the Ministry of Health did, for the first time, appoint their very own senior economic adviser, so this episode must have given them more of a fright than I thought. They also appointed a Chief Scientist to work alongside the Chief Medical Officer, and this turned out to have very important consequences for the development of health economics in the UK, but this is a story for another occasion.

\section{What has this to do with Archie Cochrane?}

What has all this to do with Archie Cochrane, you may be thinking? Well, a couple of years later, in 1970, I was back teaching public finance at the University of York, when I had a mysterious telephone call from a Medical Research Council unit in Cardiff asking me what progress I had made with my very interesting proposal about collecting population based health data to measure the effectiveness of health care. What on earth was this man talking about, I wondered. "Have you got the right person?" I asked. After all Williams is a very common (ie "popular") name! It was, of course, Archie Cochrane, who, it turned out, had been a member of the high powered group at the Ministry of Health who had run me out of town in 1968. Archie then invited himself up to York to try to persuade me to pursue this effectiveness measurement seriously, and such were his persuasive powers (backed, I should add, by money from the Nuffield Provincial Hospitals Trust and the Department of Health, who by then had also fallen under his spell) that I slowly became a health economist instead of a specialist in public finance. Archie has a lot to answer for!

But it did not stop there. Once Archie got his teeth into something he didn't easily let go. He had little difficulty in persuading me that I should stop thinking that in health care "more means better". He initiated me into the martial art of designing and conducting randomised control trials. He encouraged me to work on the development of a patient orientated outcome measure. As a quid pro quo, I did my best to convince him that costs were just as important as effectiveness. To concentrate on either without considering the other is to lead people up the garden path.

\section{Effectiveness and efficiency .... and equality}

It was precisely this line of thinking that led me to look again at Archie's thinking in the 1930 s and speculate about what it might be in the 1990s. In his best known work, Effectiveness and Efficiency ${ }^{1}$ he recounts how, when attending a rally in the 1930s in favour of setting up a National Health Service:

"I decided to go alone with my own banner. ... After considerable thought I wrote out my own slogan: ALL EFFECTIVE TREATMENT MUST BE FREE” (p 1).

I guess he was motivated by the thought that the number of effective treatments was so small that even in the economic circumstances of that time the country could easily afford to provide them, and that only by providing them free would they be distributed equitably.

But times have changed, and medical science has made rather more progress than economic science, so we face the dilemma that to do everything that is effective is beyond the means even of the richest countries in the world. So nowadays I think Archie would be prepared to concede that a better slogan would be:

ALL COST EFFECTIVE TREATMENT SHOULD BE FREE.

If you doubt whether this is a legitimate reinterpretation of the Gospel according to 
Saint Archibald, let me cite some more passages from Effectiveness and Efficiency ${ }^{1}$ :

"If ever we are going to get the 'optimum' results from our national expenditure on the NHS we must finally be able to express the results in the form of the benefit and the cost to the population of a particular type of activity, and the increased benefit that could be obtained if more money were made available. For many reasons I do not think that such an approach is possible, even on a narrow front, at present, but I wanted to aim in the right direction" (p 1$)$.

"There are two preliminary steps which are essential before this cost/benefit approach becomes a practical possibility, and it is with these two steps that I am chiefly concerned. The first is, of course, to measure the effect of a particular medical action in altering the natural history of a disease for the better... There is in addition the vast problem of the optimum use of personnel and materials in achieving these results." ( $\mathrm{p} 2)$.

From that there can be no doubt that Archie had accepted the cost effectiveness way of thinking about health care, but where precisely to go from there was rather more difficult.

Once we can quantify appropriately the value of effects and the value of resources, the problem is solved at a scientific level, though there are still problems getting these evidence based approaches accepted at a professional, political, and cultural level (as Archie discovered with his own work). But even the measurement problems caused Archie some unease. Towards the end of the book he considered how to put cost data and benefit data together so that calculations could be made: "as to how the various outputs could be increased by, say, a 10\% increase in financial allocation ... It was at this stage . . . that I used to get stuck. I knew what the next logical step was, but I found it oddly repugnant." (p 77).

He recognised that the next logical step was: "the quantification of all the various types of output" ( $\mathrm{p} 77$ ) but he was reluctant to embark upon that process. He goes on: "My conversion was due to two factors. The first was my slow acceptance of the fact that the process was being done every year unconsciously and inaccurately, and that the process must be better if done consciously. The second is the persuasive tongue of Professor Alan Williams of York..." ( $\mathrm{p} 77)$.

So my reconnaissance mission into the Ministry of Health in 1968 had not been abortive after all. God works in a mysterious way $\mathrm{His}$ wonders to perform!

\section{Convincing the doubters}

I just wish that my persuasive powers were a lot stronger, because Archie was a pushover compared with some other influential people on whom I have subsequently worked unsuccessfully, and who remain unconvinced to this day of the necessity for comprehensive quantification of health benefits (eg QALYs). And this necessity does not just derive from the notion that science requires measurement, but also that measurement leads to clarification, and clarification is essential for greater accountability. I still harbour the unworthy suspicion that part of the resistance to comprehensive quantification stems from fear of exposure. The evidence base for many decisions is very suspect, and if that frailty is exposed, the authority of the decision maker is weakened pari passu.

\section{Clinical excellence versus cost effectiveness}

As a very fitting tribute to Archie, we have the Cochrane Collaboration, and the associated promotion of evidence based medicine. I approve of both. But if invited to give three cheers for evidence based medicine, I'm afraid that I could only raise two. The trouble with it is that the evidence it deploys is almost entirely to do with effectiveness, so that the implied objective is clinical excellence no matter what the costs. Clinically excellent medicine and cost effective medicine are not the same thing. It is not difficult to think of circumstances in which offering the best conceivable treatment to a few patients will result in the health of the whole population being worse than it would have been if something rather less than the best had been offered to far more people!

If I were convinced that evidence based medicine generated clinical guidelines based throughout on cost effectiveness modes of thinking rather than just on effectiveness thinking, I would give it that extra cheer. But despite the occasional protestations of its protagonists that the guidance it offers does (in principle anyway) encompass evidence on cost effectiveness as well as evidence on effectiveness, I have yet to see any clear evidence of this. Indeed, to placate one segment of the opposition within the clinical fraternity, it has been asserted that evidence based medicine, far from being a cost cutting exercise, may actually lead to an increase in costs. What distresses me in all this is that the effectiveness issues and the cost issues are discussed separately from each other, when they should always be systematically linked.

\section{How to link costs and benefits}

I think that the best way to link costs and benefits systematically would be to go back to basics in clinical decision making and set up the decision paths in the form of decision trees. This would provide the proper framework both for the effectiveness data and for the cost data. It would also expose how little of the data we need is actually available in any robust form. Too much of it is still of the kind that $I$ encountered way back in $1968 \ldots$ ie in the form of a professional consensus that the new is better than the old. Archie taught me to go one step further, and doubt whether anything was better than doing nothing. The depth of my resulting scientific scepticism about the effectiveness of medicine is such that I am now quite agreeably surprised to discover that anything works. I start from the assumption that it doesn't! Perhaps, like many disciples, I have become more extreme than the master! 
Putting the slogan into practice

So let me return to ALL COST EFFECTIVE HEALTH CARE SHOULD BE FREE! It is not as radical a slogan as it sounds, because setting the cut off point between what is cost effective and what is not is a policy decision which I have left open. In a pluralistic society such as ours, we have to accept the existence of a private sector in health care alongside a public sector, and my slogan applies only to the public sector. In Britain, I expect (and vehemently hope) that the NHS will continue to be the dominant provider. I also expect (and hope) that its policies will continue to be broadly egalitarian in ideology. The private sector is bound to be based on some other ideology, and it will, I think, be a broadly libertarian one, namely that if people have come by their wealth in an honest manner, they should be free to spend it as they wish. The consequences of this will certainly not be egalitarian. But so long as the private sector is of minor importance for the general health status of the population this will not matter. And the best way to ensure that it is peripheral is for the NHS to concentrate its resources on the activities which are really cost effective. If these were freely available to all potential beneficiaries, the private sector could be left to provide the less cost effective things to the minority who are willing to pay for them. But I must stress once more that this depends absolutely on drawing the line between what is deemed cost effective and what is not, in such a way that the NHS is the dominant provider. I would not be happy if the NHS provided only a restricted "basic minimum" with the bulk of health care being provided as "optional extras" by the private sector.

Unless the cost effectiveness of most health care is even worse than I suspect it is, this should not be a big problem. At present the cut off point is determined indirectly by first fixing a budget limit, then working down a list of priorities until the money runs out. The trouble is that the list of priorities is not determined on cost effectiveness grounds, so we get people waiting for things that are very cost effective while activities get funded which are not at all cost effective (eg treatments which cost tens of thousands of pounds per annum just to keep one person going with a not very good quality of life).

\section{Setting a value on life}

I think it is time to move to a different strategy, and set an explicit limit on what a unit of benefit is worth. This might be a bit fuzzy at first while we are feeling our way. For instance, with average GNP per head at about $£ 10000$ per annum, why not start by saying that any activity which costs more than that per QALY gained must go to research funds for finance, and be pursued according to proper scientific protocols, reviewed by peers, and evaluated by independent scientists, not by the enthusiasts themselves. At the other extreme there will be activities which are demonstrably effective and which cost very little, and by setting a low cost per QALY borderline (say $£ 1000$ ) we could exempt them temporarily from further scrutiny. In the middle there will lie a broad range of activities which will warrant further investigation, and it is likely that as we do so both the upper and lower limits will begin to converge with the margin between the "routine" and the "experimental" probably settling at about $£ 4000$ or $£ 5000$ per QALY.

This "setting a value on life" would have to start as a set of indicative guidelines, and as experience accumulated as to the impact on the overall budget, some mutual adjustment would occur (ie as between the size of the budget and the value of a QALY at the cut off points). But any eligible health care activity that generated QALYs within the stipulated cost limit would be rated "cost effective" and should therefore be provided by the NHS. The onus of proof would have to be on the providers to produce the evidence of cost effectiveness, though at the beginning there might be a timelimited moratorium on the need for such evidence for a limited list of procedures that appeared prima facie to be so cost effective that they should be provided without question for certain specified kinds of patient. But eventually (over a 20 year period) everything should be reviewed. Who knows what skeletons might be lurking in the cupboards? The better the procedure looks, the longer the delay period could be. It would be interesting to see, within any clinical field, how procedures got rated between the three categories:

- Clearly cost effective and therefore temporarily exempt from detailed scrutiny;

- Possibly cost effective but needing investigation sooner rather than later;

- Not cost effective at present, and to be provided only within approved experimental studies.

An urgent task for the evidence based medicine community would be to devise suitable "back of the envelope" calculations to enable this initial triage to be conducted, and then to establish priorities for the middle category, and associated programme of work to ensure that they all got looked at over, say, a 10 year planning horizon.

\section{What about the distribution of health?}

There might be an objection at this point that this argument is based on the naive view that the sole objective of health care is to improve people's health, and upon the even more naive view that "improving the health of the nation" means improving it on average as much as possible. Many people would argue that the distribution of health within the community is also important, and that reducing inequalities in people's lifetime experience of health would be worth pursuing even if it meant that the average level of health were somewhat reduced as a consequence. The implication of this is that health improvements are to be weighted differently according to who gets them, and so long as the protagonists of this view accept that, and are willing to specify what the weights should be, their views can be incorporated into 
the above schema. It would simply mean that the cost effectiveness of an activity will be influenced by who benefits from it.

\section{Quantitative ethics}

Going down that road in a systematic way would require all evaluative studies to identify who enjoys the benefits and who bears the costs. For this to be manageable we need some prior agreement as to what the relevant categories of person are when it comes to reducing inequalities in health. Age, sex, and social class are obvious candidates, but what about smoking status or other lifestyle characteristics? Will we not finish up breaching one of the founding principles of the NHS, namely, that access should be on equal terms irrespective of income, etc? These are precisely the moral dilemmas the NHS is facing at present, and I think we need to develop a new branch of science, called "quantitative ethics", to help us develop "statistical compassion" as a counterweight to the excesses of individual compassion which are so distorting our communal vision at present. It seems to me extremely odd that relieving the suffering of the anonymous many should be set aside in favour of relieving the suffering of the named few. Is it that we only trust the evidence of our own eyes? If so, Cochrane's crusade for evidence based medicine (and scientific work in general) has an even harder task ahead of it than I feared.

\section{The most pressing inequalities}

On the theme of compassion, it is interesting to note that when Archie Cochrane got to the subject of "equality in health services" towards the end of his book, he took the view that social class inequalities were not the most urgent or important problem. He regarded geographical inequalities as more tractable, and differences between different types of hospital as the least excusable and the most easily remedied (teaching hospitals please note). He next mentioned "the vexed question of inequality due to variation in standard of medical care". I think it is a black mark against medical audit that so much of this type of inequality still exists. Then he turned to inequality between diseases, and this is what led him to advocate using cost-benefit ratios, so in this respect he saw efficiency and equity as going together. In a similar vein, I am sure that my proposals would improve population health overall, and increase the likelihood that every single individual would be better off than at present, but I am not so sure that they would reduce inequalities in health, though they may well do so.

But as far as I am concerned the pursuit of efficiency is a moral imperative in its own right, because it means minimising the amount of premature death and avoidable suffering in society. But I think we need to do more, and pursue, as an associated goal, the pursuit of greater equality in health between citizens. My next personal research objective is therefore to seek to elicit the sacrifices that people would be willing to make in the pursuit of greater equality in achieved lifetime health amongst the citizenry of the UK.

\section{In conclusion}

Meantime, I think it is important for those of us who feel a personal sense of obligation to Archie Cochrane to remind ourselves of his objectives and methods, and try to ensure that we behave in a manner that is worthy of him and of his scientific principles. This has led me to conclude that:

- Evidence based medicine, as currently being promoted and conducted, is not enough;

- Costs must always be considered systematically alongside effectiveness, since costs represent health gains that have been denied to others;

- Costs and effectiveness are best brought together within a decision analytic framework;

- All health care activities which meet certain minimum cost effectiveness requirements, when provided for certain specified categories of people, should be provided free within the NHS;

- A slightly less cost effective group of health care activities might also be provided for specified categories of people pending further evidence;

- All others should be treated as research activities;

- The borderlines (in cost per QALY terms) between these categories should be so drawn that the NHS remains the dominant provider of health care in the UK;

- The private sector should be left to offer the things that the NHS does not consider sufficiently cost effective to be worth providing to all eligible people.

If these proposals have Archie turning in his grave, I fondly imagine it will be because he would like to be back here helping me to pursue them! For I am sure that he would not consider the NHS to be safe in the hands of those who claim that effectiveness can't be measured and that costs can be ignored. So I hope that all of you will all be quite happy to fall in behind my Cochranesque banner, which, I am sure I need not remind you, advocates that

ALL COST EFFECTIVE TREATMENTS SHOULD BE FREE!

1 Cochrane AL. Effectiveness and efficiency. Random reflections

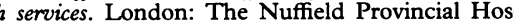
pitals Trust, 1971. The Rock Carling Fellowship 1971. 